The common practice of mixing soap solution with an antiseptic is not satisfactory in the case of the quaternary ammoniums and hibitane, but various detergents can be mixed with these compounds, if required, although most quaternary ammoniums are themselves surface-active. On the other hand, the use of soap for washing hands or the toilet of patients would have no effect on the subsequent effectiveness of these antiseptics, because it is unlikely that the amount of soap remaining on the skin after these procedures would be enough to inhibit either the quaternary ammoniums or hibitane. A very satisfactory mixture is one of hibitane and cetavlon, the latter conferring a detergent activity upon the preparation.

Because of the difficulty of defining a satisfactory strength at which the new antiseptics can be compared with the old, we have prepared Tables V and VI, showing the relationship between bactericidal power and manufacturers' recommended strengths for midwifery. The most exacting tests which we made, and also in our view the most relevant to practical obstetrics, were the $2 \frac{1}{2}$-minute contact tests between organism and antiseptic in the presence of fresh blood. By this standard none of the antiseptics tested showed a wide margin of safety, and, with the exception of hibitane, the ratio fell below 1 . It is noteworthy that bradosol, cetavlon, and roccal fell below dettol and hibitane by this standard. However, in the case of dettol, the usable concentration cannot be increased without risk of irritation, whereas bradosol, cetavlon, and roccal could probably be used at higher concentrations were it not for their cost.

Hibitane achieves a reasonable balance by giving a ratio of 1 or over for all organisms and a substantial margin of safety for the most dangerous $\beta$-haemolytic streptococcus.

One inexplicable but repeatedly confirmed result appearing in Table VI was the action of dettol on E. coli in blood for $2 \frac{1}{2}$ minutes. This excellent result was out of keeping with those obtained with other organisms. We must reiterate that none of these antiseptics would kill $\mathrm{Cl}$. tetani under conditions of contact for $2 \frac{1}{2}$ minutes, and we must emphasize again that, while hibitane, bradosol, cetavlon, and roccal can be used safely at concentrations greater than those recommended by the manufacturers, dettol cannot. Milton is, as previously stated, relatively inactive in the presence of organic material.

The final decision on which antiseptic to recommend for use in a hospital has to rest upon a balance of safety from infection, protection of patients from irritation and discomfort, acceptance by nursing staff, and reasonable economy. On the whole we feel that, after more than two and a half years' use, hibitane is the most satisfactory one available at present.

Treatment of Hands Before Putting on Operating Gloves. -Although certain units and individual surgeons may vary somewhat in their technique for "scrubbing up," there is a general measure of agreement that prolonged and careful washing and scrubbing with soap and water reduces the bacterial flora of the hands, although it has been suggested that it is possible to overdo the scrubbing and so displace deeply seated organisms. In many units after " scrubbing up " it is the practice to immerse the hands in a weakly antiseptic solution of spirit. To help render the hands aseptic we considered the possibility of glove powder containing $1 \%$ hibitane hydrochloride. After repeated tests in three individuals we were unable to convince ourselves that the addition of even such a powerful antiseptic in the dry state to glove powder was any advantage. On the other hand, we did find a considerable decrease in the number of bacteria recovered from the interior of surgical gloves if the hands had been rubbed with approximately $2 \mathrm{~g}$. of antiseptic cream (hibitane $1 \%$ ) after "scrubbing up" and before the application of formalized starch glove powder.

\section{Summary}

Consideration of antiseptics which can be used for midwifery lead to the choice of nine for test under the same conditions. Two main types of test were used:

prolonged (48 hours) and short ( $2 \frac{1}{2}$ minutes) contact in water and in the presence of protein and blood. The technical methods are described, and the results, using seven of the antiseptics on Ps. pyocyanea, E. coli, Staph. pyogenes, $\beta$-haemolytic streptococcus group $\mathrm{A}, \mathrm{Cl}$. welchii, and $\mathrm{Cl}$. tetani, are reported. Clinical trials of those selected on this basis were made. The relation of these experiments to practical midwifery is discussed. Of the two antiseptics selected for clinical trial, " Hibitane," a new British compound, tried for two and a half years, was found satisfactory, and recommendations are made for its use in watery solutions, obstetric cream, hand cream, and as an alcoholic solution suitable for instrument storage and skin preparation.

The clinical trials described in this paper were only possible with the help and interest of our obstetric colleagues and the nursing and labour ward staff. We would like to thank Miss Mason, chief pharmacist, for her patience in compounding and distributing the different preparations tried. To the laboratory staff, and in particular Miss J. Gratwick, we wish to express our thanks for technical assistance. We thank the directors of Bayer Products for advice on quaternary ammonium compounds and for supplies of roccal for testing Our thanks are also due to I.C.I. Pharmaceuticals for their willing co-operation in arriving at satisfactory preparations of hibitane and for generous supplies not only for laboratory testing but also for such prolonged clinical trial throughout the hospital.

REFERENCES

Baker, Z., Harrison, R. W., and Miller, B. F. (1941). J. exp. Med., 74, 6olebrook, L., and Maxted, W. R. (1933). J. Obstet. Gynaec. Brit. Emp., 40, 966.

Davies, G. E., Francis, J., Martin, A. R., Rose, F. L., and Swain, G. (1954). Brit. J. Pharmacol., 9, 192

Domagk, G. (1935). Disch. med. Wschr., 61, 829

Lawrence, C. A. (1950). Surface-Active Quaternary Ammonium Germicides. New York.

Rahn, O. (1947). J. Amer. pharm. Ass., Sci. Ed., 36, 134.

\title{
DIAGNOSIS OF CANCER OF LUNG AND STOMACH
}

\section{BY}

\author{
ALAN McKENZIE, M.B., B.S. \\ Medical Statistician, General Register Office
}

This paper is an account of two recent inquiries undertaken by the General Register Office-the first on cancer of the lung and bronchus, the second on cancer of the stomach.

\section{Cancer of the Lung and Bronchus}

During the past thirty years the deaths assigned to carcinoma of the lung and bronchus in this country have increased year by year until in 1954 they numbered 16,331, whereas between 1916 and 1920 they averaged only 428 per annum. What proportion of this recorded increase is real and what may be attributed to improved methods of diagnosis is a question impossible to answer in retrospect. It is, however, important to know if there is any likelihood that cancer of the lung is being overreported and whether any great number of secondary growths due to an unknown or unreported primary focus have been included. A knowledge of the degree to which the more elaborate methods of diagnosis are employed and the proportion of cases in which the diagnosis is confirmed by such procedures is of considerable interest and should help to resolve this question.

To assemble the necessary data, a covering letter explaining the reason for the inquiry, with a questionary (see below), was sent from the General Register Office to the certifying medical practitioner in respect of every second death ascribed to cancer of the lung or bronchus in January, 1955. The response showed the great 
interest of the profession in this subject ; and their cooperation, not only in providing information from their own records but also in indicating where supplementary data were available, has made this small sampling inquiry of considerable value. From 770 inquiries dispatched 654 replies were received. Additional information on diagnostic methods was provided in 634 of these.

The 634 certificates analysed below thus represent $82 \%$ of a random sample of deaths from cancer of the lung and bronchus occurring in England and Wales during the month of January, 1955: 30\% had been assigned to No. 162 (cancer of the lung and bronchus specified as primary) in the International Statistical Classification, and the remainder to No. 163 (cancer of the lung and bronchus unspecified whether primary or secondary).

Validity of Diagnosis.-If a diagnosis was made after any one of the following procedures it was classed as established: (a) bronchoscopy, (b) tumour cells discovered in sputum or pleural exudate, $(c)$ operation, $(d)$ necropsy. If diagnosis followed an $x$-ray examination or a consultation, whether in hospital or not, the diagnosis was classed as corroborated. All diagnoses made on clinical grounds only, with no mention of a second opinion, were described as unsupported.

The Sample.-An analysis of the sample used in this inquiry showed that it corresponded closely in constitution with the deaths registered in England and Wales in 1953. (a) The male/female ratio in both the present sample and the 1953 registrations was identical (male $85 \%$, female $15 \%$ ). (b) The age distribution was very similar (Table I). (c) The proportion of deaths occurring in hospital and the proportion of cases on which a necropsy was performed corresponded closely with an analysis of deaths registered in the June quarter of 1953 which was undertaken for the World Health Organization by the International Classification Centre at the General Register Office (Table HI).

TABLE I.-Age Incidence

\begin{tabular}{ll|c|c|c|c}
\hline & & Under 55 & $55-64$ & $65-74$ & 75 and Over \\
\hline $1953 \quad \ldots$ & $\ldots$ & $25 \%$ & $35 \%$ & $30 \%$ & $10 \%$ \\
Present sample & $\cdots$ & $22 \%$ & $35 \%$ & $33 \%$ & $10 \%$ \\
\hline
\end{tabular}

TABLE II

\begin{tabular}{l|c|c|c|c}
\hline & \multicolumn{2}{|c|}{ W.H.O. Analysis } & \multicolumn{2}{c}{ Present Sample } \\
\cline { 2 - 5 } & Under 65 & 65 and Over & Under 65 & 65 and Over \\
\hline $\begin{array}{l}\text { Deaths in hospital } \\
\text { Necropsy done .. }\end{array}$ & $36 \%$ & $39 \%$ & $41 \%$ & $38 \%$ \\
\end{tabular}

\section{Analysis}

In all but 18 cases ( 10 males, 8 females) the additional information supported the diagnosis of primary cancer of lung or bronchus. In eight of these cases the lung was found not to be carcinomatous, and in the remaining ten cases the lung condition was shown to be secondary to a primary elsewhere. These primary sites were: breast, two cases ; stomach, pancreas, gall-bladder, prostate, uterus, skin, and bone, each one case; and in one case the primary was not discovered.

In the eight cases wrongly diagnosed as carcinoma the diagnosis was corrected in four by a post-mortem examination made subsequent to the issue of the death certificate, and in the remaining four, where necropsy apparently confirmed the diagnosis, subsequent histopathology disproved the macroscopic findings.
The final diagnosis was primary carcinoma of the lung in 616 of the 634 cases; these are analysed in Table III, which shows the classification of diagnosis in three age groups only.

The number of cases where the diagnosis rested upon the clinical evidence of a single observer is remarkably low, especially in the age group under 65 , which accounts for more than one-half the cases. Even among those over 74, less than one-tenth were so diagnosed.

The methods by which the diagnosis was finally confirmed are shown in Table IV. In many cases more than one method was used, but each case is listed once only, and the procedures are given in what is considered the descending order of reliability.

Table III.-Diagnosis, Primary Carcinoma of Lung

\begin{tabular}{|c|c|c|c|c|c|}
\hline & \multicolumn{3}{|c|}{ Age Groups } & \multirow{2}{*}{$\begin{array}{c}\text { All } \\
\text { Ages }\end{array}$} & \multirow{2}{*}{$\begin{array}{l}\text { No. of } \\
\text { Cases }\end{array}$} \\
\hline & Under $65^{*}$ & $65-74$ & Over 74 & & \\
\hline $\begin{array}{l}\text { Unsupported .. } \\
\text { Corroborated } . . \\
\text { Established } \quad \ldots \\
\text { Changed }\end{array}$ & $\begin{array}{l}1.6 \% \\
28 \cdot 3 \% \\
67 \cdot 6 \% \\
2 \cdot 5 \%\end{array}$ & $\begin{array}{r}4.3 \% \\
46.7 \% \\
45.7 \% \\
3.3 \%\end{array}$ & $\begin{array}{r}8.2 \% \\
63.9 \% \\
24.6 \% \\
3.3 \%\end{array}$ & $\begin{array}{r}37.2 \% \\
37.8 \% \\
56 \cdot 2 \% \\
2.8 \%\end{array}$ & $\begin{array}{r}20 \\
240 \\
356 \\
18\end{array}$ \\
\hline No. of cases ... & 361 & 212 & 61 & & 634 \\
\hline
\end{tabular}

* Since the differences between the under 55 and 55-64 age groups was less than $\frac{1}{2} \%$ these two groups have been amalgamated.

TABLE IV.-Methods of Confirmation Post-mortem examination Operation

Tumour cells found in pleural exudate Bronchoscopy ".. " sputum

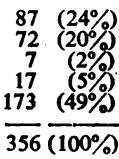

Pathology

Histological examinations of tissue were recorded in 229 cases-66 at necropsy, 44 at operation, 105 by bronchoscopy, and 13 following biopsy of a gland, etc. In 169 cases the growth was described well enough for classification under one of the following heads : adenocarcinoma, 7\% ; undifferentiated (including oat-celled, spindle-celled, spheroidal-celled, polygonal-celled, anaplastic, etc.), $58 \%$; squamous (including epidermoid), $35 \%$.

The pathological process was described under a variety of terms (more than 30 variations and combinations were met with), and it is probable that the pathologist concerned would often have disagreed with the classification adopted here. The proper allocation of such terms as "squamous metaplastic" and "undifferentiated squamous" must be more often than not a matter of personal opinion.

\section{Cancer of the Stomach}

In 1953 cancer of the stomach accounted for $18.3 \%$ of the male and $15.5 \%$ of the female deaths in England and Wales registered as due to malignant tumours. Besides being of importance as a cause of death from cancer, it is of considerable scientific interest from the way its incidence appears to vary not only from country to country but within different areas in the same country and also between the two sexes. For example, in Europe the highest death rates of men are in Switzerland and those of women in Denmark (Stocks, 1947). Switzerland, Holland, and Scandinavia have higher rates than England and Wales. Within England and Wales the highest rates are found in the rural districts and the lowest in London, which is the reverse of what is found when all cancers are considered under a single head; a similar gradient between the capital and country has been recorded in Denmark. In North Wales a higher cancer death rate than in the rest of England and Wales has been recorded for many years, and research is being undertaken into the factors that may be responsible. Whether such observations present a true picture of the relative incidence of cancer of the stomach is debatable. Certainty in diagnosis is often impossible without elaborate and, for the patient, troublesome investigation; the incidence of cancer of the stomach increases rapidly to 
old age, when it is probable that the diagnosis is more often made on clinical evidence alone. It is thus possible that there may be an appreciable error in the certification of this as a cause of death, especially at advanced ages.

The present investigation has been undertaken by the General Register Office to discover to what extent ancillary diagnostic techniques are used, and from this to estimate the possibility of mistaken certification at different ages. Similar investigations are in progress in Denmark and the Scandinavian countries. The investigation follows closely the lines of the inquiry into the diagnosis of lung cancer. A questionary (see below) and a covering letter explaining the reasons for the inquiry were sent to the certifying medical practitioner in respect of every second death registered as due to cancer of the stomach in February, 1955. From 497 inquiries sent out 437 replies were received.

The sample, though small, appears reasonably representative. The ratio of male to female deaths was $1.2: 1$, whereas in 1953 the ratio of deaths registered in England and Wales was $1.3: 1$; as is shown in Table $\mathrm{V}$, the age constitution of female deaths was close to the national pattern in 1953, though among male deaths there was an excess in the sample below 65 years and over 75 years.

TABLE V.-Age Contribution of Deaths from Cancer of Stomach

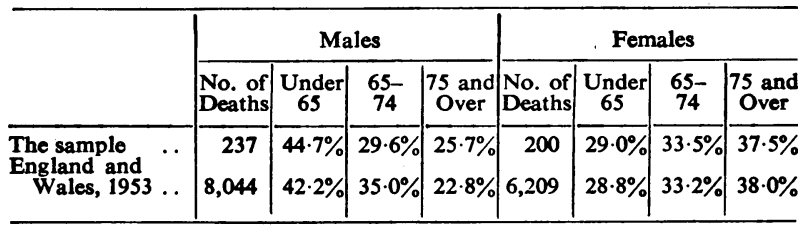

Analysis

In 13 cases ( 4 male and 9 female) inquiry revealed that the original cause as given on the death certificate was either wrong or was of very doubtful validity. In seven of these, information obtained after issue of the certificate led to a change of diagnosis. In two cases histological examination showed that what was believed at necropsy to be a malignant growth was a chronic ulcer with no signs of malignancy. In four others a necropsy was performed after issue of the certificate. In one the primary growth was discovered in the lower oesophagus, in another in the common bile duct, while in the remaining two the process was found not to be carcinomatous, hepatic necrosis having followed a perforated gall-bladder in the first and a large subdiaphragmatic abscess a pre-pyloric ulcer in the second. In five of the six doubtful cases metastases in lung, liver, or peritoneum were present, but the primary growth could not be recognized with certainty. In the remaining case it was uncertain whether any malignant process was present or not.

\section{Validity of Diagnosis}

A very arbitrary classification was used. If the diagnosis was supported by necropsy or operational findings or if the $x$-ray examination made mention of the presence of a tumour or a gastroscopy gave positive evidence, the diagnosis was classed as established. The diagnosis was described as corroborated when the $x$-ray report made no positive mention of tumour, when the supporting evidence was from a test meal or occult blood test, when a consultant confirmed the diagnosis, or if a "lump" was recorded in the epigastric region.

TABLE VI.-Validity of Diagnosis of Cancer of Stomach

\begin{tabular}{|c|c|c|c|c|c|c|c|c|}
\hline \multirow[t]{2}{*}{ ' } & \multicolumn{4}{|c|}{ Males } & \multicolumn{4}{|c|}{ Females } \\
\hline & $\begin{array}{c}\text { All } \\
\text { Ages }\end{array}$ & \begin{tabular}{|c|} 
Under \\
65
\end{tabular} & $\begin{array}{c}65- \\
74\end{array}$ & $\left|\begin{array}{c}75 \text { and } \\
\text { Over }\end{array}\right|$ & \begin{tabular}{|c|} 
All \\
Ages
\end{tabular} & $\begin{array}{c}\text { Under } \\
65\end{array}$ & $\begin{array}{l}65- \\
74\end{array}$ & $\begin{array}{l}75 \text { and } \\
\text { Over }\end{array}$ \\
\hline $\begin{array}{ll}\text { Unsupported } & . \\
\text { Corroborated } & . . \\
\text { Established } & \ldots \\
\text { Changed } & \ldots \\
\text { No. of cases } & \ldots\end{array}$ & \begin{tabular}{|l|}
$8.4 \%$ \\
$30.4 \%$ \\
$59.5 \%$ \\
$1.7 \%$ \\
237
\end{tabular} & \begin{tabular}{|c|}
$2.8 \%$ \\
$18.9 \%$ \\
$77.3 \%$ \\
$0.9 \%$ \\
106
\end{tabular} & \begin{tabular}{|c|}
$7.1 \%$ \\
$28.6 \%$ \\
$62.8 \%$ \\
$1.4 \%$ \\
70
\end{tabular} & \begin{tabular}{|c|}
$19 \cdot 7 \%$ \\
$52.5 \%$ \\
$24.6 \%$ \\
$3.3 \%$ \\
61
\end{tabular} & \begin{tabular}{|l|}
$18 \%$ \\
$39 \cdot 5 \%$ \\
$38 \%$ \\
$4.5 \%$ \\
200
\end{tabular} & \begin{tabular}{|c|}
$5.7 \%$ \\
$25.9 \%$ \\
$63.8 \%$ \\
$5.2 \%$ \\
58
\end{tabular} & \begin{tabular}{|c|}
$9.0 \%$ \\
$43.3 \%$ \\
$41.8 \%$ \\
67 \\
67
\end{tabular} & $\begin{array}{l}36 \% \\
46.7 \% \\
14.7 \% \\
2.6 \% \\
75\end{array}$ \\
\hline
\end{tabular}

If the diagnosis was made on purely clinical grounds and without any such confirmatory evidence it was described as unsupported. The analysis is shown $i_{1}$ Table VI. The most striking feature is the disparate treatment of men and women. The diagnosis was classed as established in $60 \%$ of male deaths but in less than $40 \%$ of female, while unsupported diagnoses were a little more than $8 \%$ in the male certificates but $18 \%$ in the female. The same pattern is seen in each age group. It seems improbable that the medical profession can be held responsible for this discrimination and more likely that the solution will be found in the traditional feminine ability to bear pain and discomfort

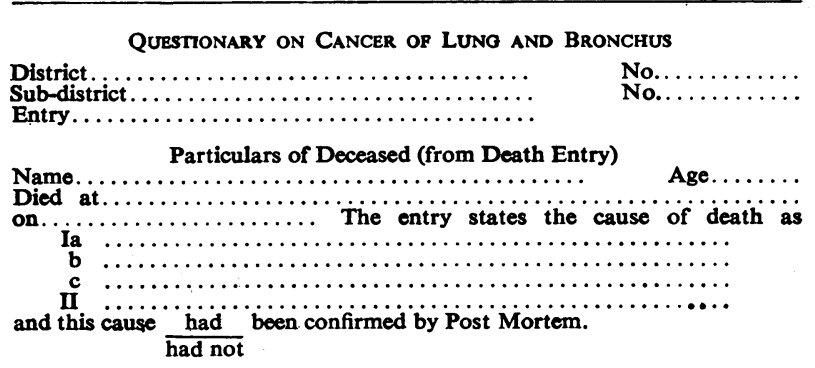

I. By which of the following means was the diagnosis arrived at or confirmed: (Please tick each square where appropriate)

a. Clinical examination

b. $X$-ray

c. Bronchoscopy

d. Tumour cells discovered in sputum

e. Tumour cells discovered in plural exudate

f. Operation

g. Post Mortem only

h. Other (please specify) $\ldots \ldots \ldots \ldots \ldots \ldots \ldots \ldots \ldots \ldots \ldots \ldots \ldots$

II. Do you consider that the growth was

a. Primary in the lung or bronchus ?
b. Secondary to a primary focus outside the lung ?
If b please specify primary site.....................

If b please specify primary site......................

(a) Bronchoscopy

(b) Operation

If so, please state the pathologist's classification of the tumour

2. Did histological examination suggest any particular origin of

Did histological examination suggest any particular origin of
the tumour

If so, please specify the tissue ........................... Have you any other observations you consider of special interest
IV.

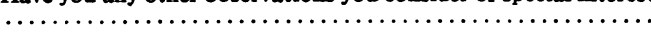

V. If you are unable yourself to reply to the above questions would you please indicate where the information may be obtained

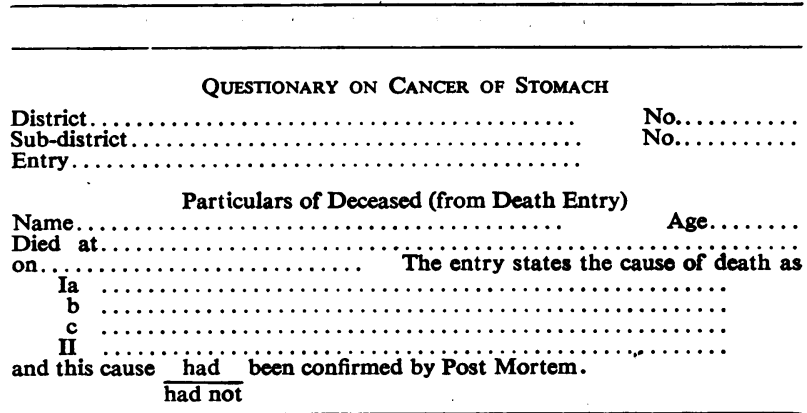

I. By which of the following means was the diagnosis arrived at or confirmed: (Please tick each square where appropriate)
a. Clinical examination only
b. $X$-ray
c. Gastroscopy
d. Presence of occult blood
e. Test meal
f. Operation
g. Post Mortem only

II. Was any histological examination made following :

a. Biopsy (at operation or otherwise)

b. Post Mortem

If so, please state the pathologist's classification of th: 2 tumour

III. Have you any other observations you consider of : cial interest

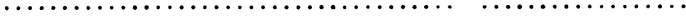

IV. If ou are unable yourself to reply to the above ques.ions will you please

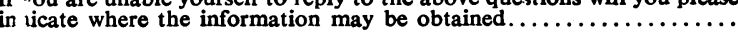


without complaint. Strong support for this suggestion is seen in figures derived from the National Cancer Registration Scheme, which mainly records those who seek hospital treatment, where the ratio of male to female registrations has varied in recent years from $1.6: 1$ to $1.8: 1$ while the ratio of male to female deaths from cancer of the stomach remains constant at $1.3: 1$.

In each sex the proportion of established diagnoses falls with increasing age. In men under the age of 65 threequarters were so classified, but only one-quarter of those of 75 years and onwards; the corresponding figures for women were two-thirds and one-seventh. The unsupported diagnosis correspondingly increases, being seven times more frequent among men in the 75 years and over group than in the under 65 's and rather more than six times in women. These figures clearly show that ancillary methods of diagnosis are much less often employed among older than among younger persons, and it is reasonable to conclude that diagnosis is similarly less accurate. Since about a quarter of male and a third of female deaths attributed to cancer of the stomach are recorded in persons of 75 years and more, the error may be considerable. The exact significance of this finding is difficult to assess. Willis (1953), in an analysis of 1,000 necropsies where cancer had been diagnosed clinically or discovered at necropsy, found that a correct clinical diagnosis of cancer of the stomach had been made in $70 \%$ of proved cases only, that in the series the disease had been missed in life in 40 cases and wrongly diagnosed in 46 , so that the false positives practically cancelled the missed diagnoses. This, of course, was in a hospital practice, and the majority of cases had been more fully investigated than is possible in general practice, where it is by no means certain that the results would be comparable.

\section{Conclusions}

Among the cases of cancer of the lung and bronchus reviewed here the standard of diagnostic technique was high : in only $3 \%$ had no confirmatory procedure been adopted and, as might be expected, most of these were found in the oldest age groups. In $56 \%$ of all cases and $67 \%$ of those under 65 the diagnosis had been confirmed by a technique that permitted the minimum of error. In only eight cases did the inquiry show the original diagnosis of cancer to have been incorrect; in a further 10 the growth in the lung was found to be secondary to a primary focus elsewhere.

It seems clear that cancer of the lung and bronchus is not being over-reported on death certificates, but it is not possible to conclude if the disease is still being under-reported, as most probably happened in the past. Not infrequently the diagnosis of bronchial cancer is not made until after a post-mortem examination, and it is probable that the true numbers are still greater than appear from the death registrations.

The only conclusion that can be drawn from the inquiry on stomach cancer is that the certification of death from this cause is less likely to be accurate among older than among younger persons, and that in a large proportion of those who die aged 75 years or more this diagnosis cannot be regarded with complete confidence. There is, howe er, no reason to assume that calculated death rates at hese ages deviate appreciably from the truth.

The success of the inquiries is largely due to the assistance given by the medical practitioners, pathologists, and consultants who so carefully provided the information on which they were based.

\section{REFERENCES}

Stocks, P. (1947). General Register Office, Studies on Medical and Population Subjects No. 1. Regional and Lncal Differences in Cance Death Rates. H.M.S.O., London.

Willis, R. A. (1953). Pathology of Tumours, 2nd ed. Butterworth, London.

\section{REASSESSMENT OF EFFECT OF FATTY MEALS ON BLOOD COAGULABILITY}

BY

\author{
G. H. HALL, M.B., B.Sc., M.R.C.P. \\ Lately, Squadron Leader, R.A.F. Institute of Pathology \\ and Tropical Medicine
}

Duguid's $(1949,1952,1955)$ theory of the pathogenesis of certain types of atherosclerosis requires as a first step in the process the deposition of fibrin thrombi on arterial linings. Fullerton (1955) has discussed the possibility that such thrombi may form during periods of intense lipaemia, on the basis that blood coagulability has been found to be increased after fatty meals (Fullerton, Davie, and Anastasopoulos, 1953). In these experiments blood coagulability was assessed by the measurement of clotting-times of whole blood in silicone-lined tubes and estimation of the accelerated clotting-time (" prothrombin " time) of a mixture of the plasma under test with Russell viper venom and calcium chloride. Attention is drawn to the techniques employed because under these experimental conditions the role of platelets is unduly minimized. In silicone-lined tubes platelet rupture is incomplete and greatly delayed, and plasma collected in the usual way in plain glass tubes contains very few available platelets for participation in later, artificially provoked, clotting.

In view of the known importance of platelets in the formation of thrombi, it was thought worth while repeating these experiments while taking precautions to ensure that the contribution of platelets to the formation of a clot was fully expressed. This was done by measuring the clotting-times of whole blood in plain glass tubes, the surfaces of which excite platelet breakdown, and by estimating the accelerated clotting-times of platelet-rich plasma, collected in siliconized apparatus and not put into contact with a plain glass surface until shortly before clotting is brought about. Accelerated clotting-times of platelet-deficient plasma were also estimated for the purpose of comparison.

\section{Reagents and Methods}

Fifteen subjects were investigated, 18 tests being done in all. Blood was withdrawn immediately before and from one to three hours after the ingestion of a fatty meal. In most instances this consisted of two fried eggs, bacon. fried bread, bread-and-butter, and milk; in a few cases the intake of fat was slightly less than this. The development of satisfactory lipaemia was checked by naked-eye examination of the plasma and, as is shown below, the reduction of accelerated clotting-times of platelet-deficient plasma. Venesections were carried out with siliconized needles and syringes, and the blood dispensed as follows: (1) Three lots of $1 \mathrm{ml}$. into Lee and White clotting-tubes $\left(3\right.$ by $\frac{3}{8}$ in. -7.5 by $1 \mathrm{~cm}$.) and the clotting-times measured in a $37^{\circ} \mathrm{C}$. waterbath. (2) $4.5 \mathrm{ml}$. into $0.5 \mathrm{ml}$. of $3.8 \%$ sodium citrate in a silicone-lined tube, and the plasma separated by centrifuging at 1,500 revolutions a minute for 10 minutes (platelet-rich plasma). (3) $4.5 \mathrm{ml}$. into $0.5 \mathrm{ml}$. of $3.8 \%$ sodium citrate in a plain glass tube, and the plasma separated by centrifuging at 3,000 revolutions a minute for. 20 minutes (plateletdeficient plasma).

The accelerated clotting-times were obtained by mixing $0.1-\mathrm{ml}$. quantities of plasma, 1 in 10,000 Russell viper venom in $0.9 \%$ saline, and $\mathrm{M} / 40$ calcium chloride. The plasma was allowed to react with the Russell viper venom for one minute before the addition of the calcium chloride, to 